Revta brasil. Bot., São Paulo, V.24, n.1, p.43-49, mar. 2001

\title{
Biologia reprodutiva de Calibrachoa elegans (Miers) Stehmann \& Semir (Solanaceae) ${ }^{1}$
}

\author{
JOÃO RENATO STEHMANN ${ }^{2,4}$ e JOÃO SEMIR ${ }^{3}$
}

(recebido: 20 de abril de 2000; aceito: 4 de outubro de 2000)

\begin{abstract}
Reproductive biology of Calibrachoa elegans (Miers) Stehmann \& Semir (Solanaceae)). Calibrachoa elegans is an endemic annual species from the "canga" region in the iron quadrangle, Minas Gerais, Brazil. The study of its reproductive biology involved cross-pollination experiments, self-incompatibility tests and observations of the pollination process. Results of manual pollination experiments showed that the studied population is allogamous. Interruption of pollen tube growth in the style of self-pollinated flowers confirmed the occurrence of self-incompatibility reactions. Pollination is effected only by females of Hexantheda missionica (Colletinae, Apoideae), which show high fidelity to flowers of $C$. elegans; males use the flowers as a nectar source, as stops between flights when searching for females, and as shelter during the night. They prepare the shelter by cutting and removing anthers and style. The populations of Hexantheda missionica found in Minas Gerais are the first records of this species for southeastern Brazil and probably represent remnants that reached this region during the past, but are now disjunct and isolated from those in southern Brazil.
\end{abstract}

RESUMO - (Biologia reprodutiva de Calibrachoa elegans (Miers) Stehmann \& Semir (Solanaceae)). Calibrachoa elegans é uma espécie anual, endêmica da região da canga do quadrilátero ferrífero de Minas Gerais, Brasil. O estudo da sua biologia reprodutiva envolveu experimentos de cruzamentos, teste do sistema de auto-incompatibilidade e observação do processo de polinização. Os experimentos realizados através de polinizações manuais indicam que a população estudada é preferencialmente alógama. A interrupção do crescimento do tubo polínico no estilete das flores autopolinizadas, verificada através da microscopia de fluorescência, confirmou a ocorrência de reação de auto-incompatibilidade. A polinização é realizada apenas pelas fêmeas de Hexantheda missionica (Colletinae, Apoideae), uma abelha com alta fidelidade de visita às flores de C. elegans. Os machos desta espécie utilizam as flores como fonte de néctar, como local para pouso entre os vôos de patrulhamento a procura de fêmeas para acasalamento e como abrigo noturno. Para se acomodarem na flor, geralmente cortam e removem os estames e o estilete. As populações de Hexantheda missionica encontradas em Minas Gerais são o primeiro registro da espécie para a região sudeste do Brasil e, provavelmente, representam remanescentes que chegaram a esta região no passado e que agora se encontram disjuntas e isoladas das populações da região sul do Brasil.

Key words - Reproductive biology, conservation, biogeography, Hexantheda missionica, Calibrachoa elegans

\section{Introdução}

Calibrachoa La Llave \& Lex. pertence à tribo Nicotianeae, subfamília Cestroideae, e a maioria das suas 24 espécies ocorre na região subtropical da América do Sul (Stehmann 1999). Diversas espécies de Calibrachoa estavam incluídas em Petunia Juss., gênero que foi desmembrado por Wijsman \& Jong (1985). Esses autores reconheceram a existência de dois grupos de espécies geneticamente distintos em Petunia s.l. e propuseram tratá-los como gêneros

1. Parte da tese de doutorado de J.R. Stehmann desenvolvida na Universidade Estadual de Campinas.

2. Universidade Federal de Minas Gerais, Instituto de Ciências Biológicas, Departamento de Botânica, Caixa Postal 486, 31270-901 Belo Horizonte, MG, Brasil. Bolsista CAPES/ PICD (1993-1996).

3. Universidade Estadual de Campinas, Instituto de Biologia, Departamento de Botânica, Caixa Postal 6109, 13081-970 Campinas, SP, Brasil.

4. Autor para correspondência: stehmann@icb.ufmg.br diferentes. Petunia nyctaginiflora Juss. foi conservada como tipo nomenclatural do gênero Petunia (Brummitt 1989) e reteve as espécies com número cromossômico $\mathrm{n}=7$ e com prefloração imbricada. Para Calibrachoa foram recombinadas as espécies com número cromossômico $\mathrm{n}=9$ e com prefloração conduplicada (Wijsman 1990, Stehmann \& Semir 1997).

Estudos abordando a biologia reprodutiva das espécies de Calibrachoa são escassos e há informação sobre o sistema de cruzamento de apenas três espécies (Ferguson \& Otley 1932, Wijsman et al. 1983) e a polinização de duas espécies do sul do Brasil (Wittmann et al. 1990).

Calibrachoa elegans é uma espécie endêmica da canga do quadrilátero ferrífero de Minas Gerais $\mathrm{e}$, juntamente com C. linoides (Sendtn.) Wijsman, possui a distribuição mais setentrional do gênero na América do Sul (Stehmann 1999). Foi incluída na lista de espécies ameaçadas de extinção do Estado de Minas Gerais, na categoria "criticamente em perigo", citada como Petunia elegans Miers 
(COPAM 1997). O objetivo deste trabalho foi contribuir para o conhecimento da biologia reprodutiva desta espécie, através do estudo dos sistemas de cruzamentos, de auto-incompatibilidade e do processo de polinização.

\section{Material e métodos}

A área de estudo onde foi observada a polinização e realizou-se os experimentos para teste dos sistemas reprodutivos localiza-se no Município de Brumadinho, no estado de Minas Gerais $\left(20^{\circ} 05^{\prime} 33^{\prime \prime} \mathrm{S}\right.$ e $\left.43^{\circ} 59^{\prime} 41^{\prime \prime} \mathrm{W}\right)$, numa altitude de 1450 m.s.m. A paisagem da região é montanhosa, possuindo relevo fortemente ondulado, e dominada por vegetação campestre denominada campo ferruginoso sobre canga nodular (Rizzini 1979). O clima da região é do tipo $\mathrm{Cwb}$, tropical de altitude com chuvas de verão e verão fresco e estação seca bem definida.

A descrição morfológica de Calibrachoa elegans baseou-se no estudo de material vivo, bem como de exsicatas da coleção do herbário UEC do Departamento de Botânica do Instituto de Biologia Vegetal da Universidade Estadual de Campinas (UNICAMP). Os materiais representativos da população estudada, J. R. Stehmann 1160, 1284, 1388, 1429, encontram-se depositados no referido herbário. Informações fenológicas foram obtidas dos registros do herbário e de visitas ao local de estudo em diferentes épocas do ano.

A antese das flores de C. elegans foi observada em dez botões marcados. A receptividade do estigma foi testada com a aplicação de peróxido de hidrogênio 3\% (Zeisler 1938). Os grãos de pólen de dez flores de indivíduos diferentes foram fixados em FAA 50 e corados com carmim acético para se testar a viabilidade. A viabilidade do pólen dos estames maiores, intermediários e do menor foi analisada separadamente. Para detecção da presença de osmóforos utilizou-se vermelho-neutro diluído em água na proporção 1 g.L.L (Vogel 1962).

Para o estudo do sistema reprodutivo foram realizados tratamentos através de polinizações manuais: autopolinização (incluindo geitonogamia) e polinização cruzada. As flores foram emasculadas para se testar a ocorrência de agamospermia. A autopolinização espontânea foi avaliada através do ensacamento de botões em pré-antese. Para todos esses os tratamentos, os botões florais foram envolvidos em sacos de organza de náilon, doze horas antes do experimento. Na polinização natural (controle), os botões foram apenas marcados e não ensacados. Os resultados foram avaliados através da formação ou não de frutos. O ovário e o estilete de cinco flores submetidas a autopolinização e polinização cruzada foram coletados após 24 e 48 horas e fixados em FAA 50 para observação da germinação e do crescimento do tubo polínico ao microscópio de fluorescência (Martin 1959).

O trabalho de campo para a observação dos visitantes florais foi realizado nos meses de outubro e novembro de 1993, durante quatro dias, no período das 6 às $18 \mathrm{~h}$, perfazendo um total de aproximadamente 48 horas de observação diurna. O comportamento geral dos visitantes foi descrito após a visualização direta e repetida dos fenômenos. Amostras da carga polínica dos visitantes florais foram analisadas, removendo-se o pólen do corpo do visitante com gelatina glicerinada e posteriormente montandose lâminas semipermanentes para a identificação do pólen. Os materiais testemunhos dos visitantes florais foram depositados nos Museus de História Natural da UNICAMP e da Pontifícia Universidade Católica do Rio Grande do Sul.

\section{Resultados}

Calibrachoa elegans é uma espécie anual, homóica, de porte herbáceo que em geral não ultrapassa os $50 \mathrm{~cm}$ de altura. O caule é inicialmente único e ereto, mas pode ramificar a partir da base, tornandose muito ramoso e tardiamente decumbente. As folhas são lineares, linear-oblongas ou linear-elípticas, revolutas e recobertas por denso indumento na face abaxial. As flores são hermafroditas e estão reunidas em inflorescências cimosas, compostas de monocásios de tamanhos diferentes. A corola é zigomorfa, infundibuliforme, possuindo tubo de 13 a 15 $\mathrm{mm}$ comprimento e um limbo de 17 a $19 \mathrm{~mm}$ de diâmetro, pentalobado e de coloração magenta. A abertura do tubo da corola apresenta formato semilunar e possui cerca de 5 a $6 \mathrm{~mm}$ de diâmetro. A fauce apresenta coloração esbranquiçada e é circundada por um anel azul-violáceo que, juntamente com as anteras amarelas, constituem guias de néctar. $\mathrm{O}$ androceu é formado por cinco estames de tamanhos desiguais, um menor, dois intermediários e dois maiores, adnatos 3 a $4 \mathrm{~mm}$ à base da corola, onde delimitam cinco ductos interestaminais (figura 1). $\mathrm{O}$ gineceu apresenta um ovário ovóide com um disco nectarífero bilobado basal, estilete com 9 a $10 \mathrm{~mm}$

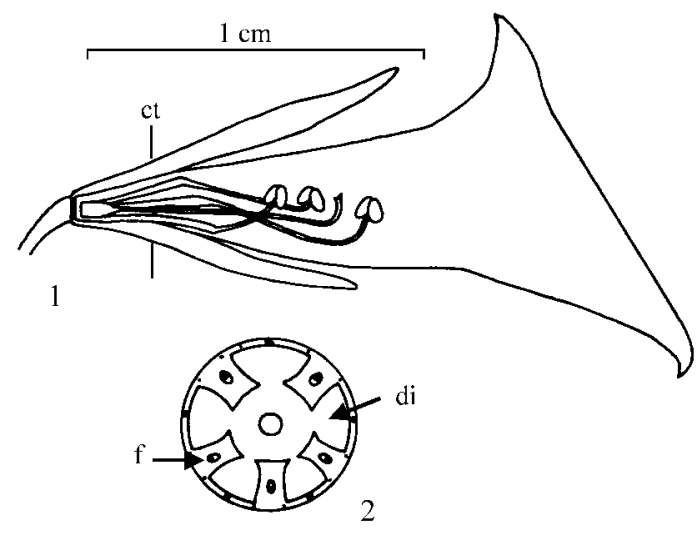

Figuras 1-2. Calibrachoa elegans. 1. Corte longitudinal da flor mostrando a posição dos estames heterodínamos e do gineceu. 2 . Representação esquemática da base do tubo da corola, vista em corte transversal (ct), mostrando os cinco ductos interestaminais (di) delimitados pelos filetes (f). 
de comprimento, com ápice curvo ou recurvado e estigma truncado, curta e desigualmente bilobado dorso-ventralmente. O fruto é capsular e apresenta pedúnculo reflexo, sendo as sementes liberadas diretamente ao solo abaixo ou próximo à planta mãe. Cada fruto pode conter entre 10 a 20 sementes de 1,2 a $1,3 \mathrm{~mm}$ de comprimento.

Calibrachoa elegans pode ser encontrada em flor de setembro a maio, mas o período de florescimento mais intenso corresponde aos meses de outubro, novembro e dezembro. A frutificação ocorre geralmente a partir de novembro e prolonga-se por todo o período do verão. Com a chegada da estação seca, a partir de maio, a planta fenece. As flores de C. elegans podem permanecer abertas por cinco dias. A abertura da corola ocorre assincronicamente na população e em diferentes horários do dia. As flores do primeiro dia geralmente apresentam uma forma estrelada, com os lobos da corola plissados em vista frontal. Nos dias subsequentes, o limbo abre-se completamente e os lobos tornam-se totalmente distendidos. O néctar é viscoso e produzido em quantidade muito pequena, motivo pelo qual o volume e a concentração de solutos não foram quantificados. A deiscência das anteras é longitudinal e ocorre logo após a abertura da corola, primeiro nas anteras dos estames maiores e intermediários e posteriormente na antera do estame menor. $\mathrm{O}$ gineceu é um pouco menor que $\mathrm{o}$ androceu e o estilete apresenta o ápice curvo, tornando-se posteriormente recurvo. O estigma é úmido e encontra-se receptivo já no botão floral, pouco antes da abertura da corola. O estigma e as anteras encontram-se muito próximos, a cerca de 1 a $3 \mathrm{~mm}$ de distância (figura 2). Osmóforos não foram detectados nas flores e nenhum odor pôde ser percebido.

A viabilidade do pólen analisado foi alta $(92,84 \%)$ e não houve diferença significativa na viabilidade do pólen entre as flores (ANOVA $\mathrm{F}=1,909 ; \mathrm{P}=0,179 ; \mathrm{GL}=2 ; \mathrm{n}=30$ ) ou entre os estames de tamanhos diferentes (ANOVAF $=0,054$; $\mathrm{P}=0,947 ; \mathrm{GL}=2 ; \mathrm{n}=30$ ).

Os testes para verificar o sistema reprodutivo mostraram que a população estudada é preferencialmente alógama (tabela 1). As flores emasculadas e as autopolinizações espontâneas não produziram frutos. As flores que foram submetidas a polinização cruzada tiveram um alto sucesso na produção de

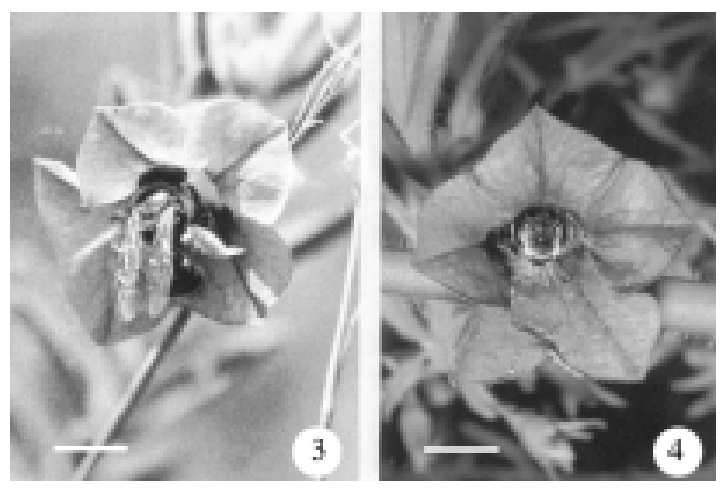

Figuras 3-4. Hexantheda missionica. 3. Fêmea coletando pólen. 4. Macho utilizando o interior da flor como abrigo para o pernoite. Escala: $5 \mathrm{~mm}$.

frutos, enquanto que o sucesso das flores que foram submetidas a autopolinizações manuais foi muito baixo. Os poucos frutos formados através deste último tratamento apresentaram tamanho bastante reduzido e a formação de pouca ou nenhuma semente. Não pode ser descartada a possibilidade deles serem produtos de contaminação. As flores marcadas e não ensacadas produziram uma quantidade menor de frutos do que as flores que foram submetidas a polinização cruzada manual.

As observações da germinação do pólen e do crescimento do tubo polínico indicam que ocorreu uma reação de auto-incompatibilidade no estilete. Nas flores autopolinizadas, 24 horas após a polinização, o pólen germinou e o tubo polínico desenvolveu-se até atingir o terço inferior do estilete, onde cessou seu crescimento e foram visualizados espessamentos de calose. Nas flores que foram submetidas a polinização cruzada, após o mesmo período de

Tabela 1. Tratamentos realizados para testar o sistema reprodutivo de Calibrachoa elegans, mostrando o número de flores utilizadas, frutos obtidos e o sucesso (\%) alcançado na formação de frutos.

\begin{tabular}{lccc}
\hline Tratamento & Flores $\left(\mathrm{n}^{\mathrm{o}}\right)$ & Frutos $\left(\mathrm{n}^{\mathrm{o}}\right)$ & Sucesso $(\%)$ \\
\hline Polinização cruzada & 27 & 22 & 81,48 \\
$\begin{array}{l}\text { Autopolinização } \\
\text { manual }\end{array}$ & 37 & 2 & 5,41 \\
$\begin{array}{l}\text { Autopolinização } \\
\text { espontânea }\end{array}$ & 12 & 0 & 0 \\
$\begin{array}{l}\text { Agamospermia } \\
\begin{array}{l}\text { Polinização natural } \\
\text { (controle) }\end{array}\end{array}$ & 14 & 0 & 0 \\
\hline
\end{tabular}


tempo, os tubos polínicos já haviam atingido o ovário e os óvulos.

As flores de Calibrachoa elegans foram visitadas quase que exclusivamente por uma espécie de abelha, Hexantheda missionica Oglobin (Colletinae, Apoideae, Hymenoptera). Além dela, apenas outros dois visitantes ocasionais foram observados. Um lepidóptero realizou três visitas no horário próximo do meio-dia e uma mamangava (Bombus sp.) tentou sem sucesso pousar sobre a corola. Diversas espécies de abelhas, incluindo Apis mellifera, foram observadas em atividade visitando flores de outras espécies de plantas das proximidades, mas nunca as flores de C. elegans.

As visitas de Hexantheda missionica iniciam-se após as 9:00 h da manhã, sendo mais intensas entre 10:00 e 11:00 h e terminam antes das 17:00 h. Os machos desta espécie distinguem-se das fêmeas pelo seu maior porte e por apresentarem dois tufos de pêlos esbranquiçados acima das mandíbulas. O comportamento das fêmeas e dos machos é bastante diferenciado.

As fêmeas de C. elegans coletam ativamente o pólen, que é armazenado nas escopas localizadas nas pernas traseiras e no abdômen (figura 3). O tempo de permanência nas flores depende principalmente da quantidade de pólen disponível. O tempo de visita é geralmente maior nos primeiros horários de atividade da manhã, quando uma visita pode durar até três minutos, declinando em direção ao final da manhã, quando as visitas tornam-se breves, durando apenas poucos segundos. $\mathrm{Na}$ análise do pólen carregado pelas fêmeas, encontrou-se exclusivamente pólen de C. elegans.

Os machos utilizam as flores como fonte de néctar, local para pouso entre os vôos de patrulhamento a procura das fêmeas para acasalamento e como abrigo noturno. As flores utilizadas pelos machos como abrigo duram até dois dias e eles geralmente cortam e removem os estames e o estilete antes de se acomodarem no interior do tubo da corola ao final da tarde. Este dano provavelmente induz a senescência da flor. Em geral eles entram no tubo da corola de ré, posicionando a cabeça próxima à abertura do tubo (figura 4). As mesmas flores utilizadas para abrigo, bem como outras próximas, são comumente utilizadas como fonte de néctar durante a atividade de patrulhamento. Elas constituem a base para pouso entre os vôos de patrulhamento a procura de fêmeas. Mais raramente outros tipos de substratos são utilizados para pouso. O tempo de duração do patrulhamento, assim como o de alimentação, é bastante variável. Os padrões observados foram os seguintes: os vôos de patrulhamento duraram 20 a $60 \mathrm{~s}$, os de alimentação entre 15 a 40 s e a espera na base de pouso antes do patrulhamento de 1 a 60 s. Durante o patrulhamento, o macho sobrevoa diversas flores a procura de fêmeas e ao localizar alguma, mergulha em sua direção na tentativa da cópula. Ao encontrarem outros machos nas flores durante o patrulhamento, estes se repelem imediatamente, mas sem um aparente comportamento agonístico. $\mathrm{O}$ estudo da carga polínica dos machos $(\mathrm{N}=10)$ encontrou apenas esparsos grãos espalhados pelo corpo.

A polinização parece ser realizada pelas fêmeas de $H$. missionica, quando contacta o estigma com suas escopas ventrais abdominais carregadas de pólen (polinização esternotríbica). A presença de um estame menor interno, característica encontrada na maioria das espécies do gênero, força a fêmea a entrar inteiramente no tubo da corola para realizar a coleta do pólen. Os machos não participam da polinização, pois não armazenam pólen em seu corpo, limpam-se constantemente e utilizam comumente as mesmas flores na sua rota a procura de fêmeas, flores estas geralmente danificadas e desprovidas de estames e de estilete.

\section{Discussão}

A população estudada de Calibrachoa elegans é polinizada unicamente por Hexantheda missionica, uma abelha oligolécita. A população desta abelha observada neste trabalho corresponde ao primeiro registro da ocorrência da espécie no sudeste do Brasil, já que ela era conhecida apenas da região sul do Brasil e do norte da Argentina (Michener 1989). Pouco se conhece sobre a sua biologia e seu ninho ainda não foi descrito. Como as mandíbulas das espécies de Colletinae são fortes e adaptadas a cavar (Roubik 1989), acredita-se que H. missionica nidifique em buracos escavados no solo.

Silva (1994) registrou visitas de uma espécie Hexantheda sp. (não identificada) nas flores de uma população de Petunia integrifolia estudada no Rio Grande do Sul, espécie que possui flores morfologi- 
camente muito semelhantes às de $C$. elegans. Nesta espécie, tanto os machos como as fêmeas tocam o estigma ao entrarem na corola para obter néctar e foram considerados polinizadores de $P$. integrifolia. Em C. elegans, contudo, os machos não participam do processo de polinização, visto que não guardam o pólen no seu corpo, e apenas as fêmeas de $H$. missionica têm relação direta no processo de polinização.

A utilização das flores de Calibrachoa como abrigo noturno já foi relatada por Schlindwein (1995) para C. ovalifolia (Miers) Stehmann \& Semir (citada como Petunia ovalifolia), espécie que habita a região pampeana no sul do Brasil. Segundo este autor, machos de Lanthanomelissa goeldiana (Anthophoridae) utilizam a flor desta espécie como abrigo para o pernoite. Segundo Dafni et al. (1981), que estudaram a polinização de Serapias vomeracea (Orchidaceae) realizada por abelhas que "dormem" nas flores, o interior da flor provavelmente simula buracos no solo, locais onde as abelhas solitárias costumam buscar abrigo para passar a noite.

A flor da maioria das espécies de Calibrachoa é estruturalmente muito semelhante, possuindo corola infundibuliforme, zigomorfa, coloração magenta ou purpúrea, ductos interestaminais curtos (com menos de $5 \mathrm{~mm}$ de comprimento) e estames heterodínamos com estigma posicionado entre as anteras (Stehmann 1999). Pode-se sugerir que as espécies com estas características sejam, assim como $C$. elegans, também polinizadas por abelhas. Apenas uma espécie, C. parviflora (Juss.) Wijsman, é reconhecidamente autógama e não necessita de agentes polinizadores (Ferguson \& Ottley 1932, Wijsman et al. 1983). Os indivíduos desta espécie possuem flores muito reduzidas, com menos de $1 \mathrm{~cm}$ de comprimento, e são ruderais. Outras duas espécies de Calibrachoa, C. sendtneriana (R. E. Fr.) Stehmann \& Semir e C. serrulata (L. B. Sm. \& Downs) Stehmann \& Semir, possuem flores vermelhas (Smith \& Downs 1966, Stehmann 1999) e são provavelmente polinizadas por aves.

Entre os atributos morfológicos relacionados à melitofilia encontrados nas espécies de Calibrachoa, merecem destaque a coloração da corola e os estames heterodínamos. A maioria das espécies melitófilas do gênero possui corola com limbo magenta ou púrpura e intensa luminância (iridescência) quando expostas à luz do sol. De acordo com Wittmann et al. (1990), a presença de um quarto receptor nos olhos compostos de Callonychium petuniae (Colletinae) permite a essa espécie enxergar o vermelho presente nas flores purpúreas de Petunia s.l. e constitui-se numa evidência de um processo de especialização ou coevolução. A maioria das espécies de abelhas possui somente três receptores e não percebe o vermelho (Kevan 1983, Chittka \& Menzel 1992). Não há estudos sobre a presença de diferentes receptores nos olhos de Hexantheda missionica. Com relação à organização do androceu, a presença de um estame menor incluso na flor de $C$. elegans parece obrigar a fêmea a entrar inteiramente no tubo para coletar o pólen de suas anteras e pode favorecer a deposição do pólen armazenado nas escopas abdominais no estigma e, consequentemente, a polinização.

Analisando as informações sobre a distribuição geográfica de Calibrachoa elegans e das outras espécies do gênero, bem como das populações de Hexantheda missionica, podemos observar que as populações encontradas em Minas Gerais constituem as mais setentrionais de ambos os gêneros na América do Sul. Hexantheda missionica é conhecida apenas no sul do Brasil e nas províncias de Misiones e Formosa no norte da Argentina (Michener 1989). Tais dados sugerem que Calibrachoa e Hexantheda tenham uma história biogeográfica comum.

A história evolutiva do gênero Calibrachoa, particularmente das espécies com corola purpúrea, está provavelmente ligada à história evolutiva dos grupos de polinizadores, especialmente aos grupos de abelhas solitárias. A especialização ou coevolução ocorrida entre abelhas e as espécies purpúreas de Petunia s.l. (Wittmann et al. 1990) pode ter sido um fator de confinamento e restrição à expansão da distribuição geográfica das espécies melitófilas do gênero. Segundo Roubik (1989), a riqueza e a distribuição subtropical de diversos grupos de abelhas predominantemente temperados é o reflexo de uma ocupação ocorrida nos períodos glaciais pleistocênicos. Evidências baseadas em estudos palinológicos relatam que as planícies e planaltos do sudeste do Brasil, hoje cobertos por cerrado e floresta semidecídua tropical, foram substituídos por campos subtropicais e floresta de galeria durante o último período glacial, indicando um clima relativamente 
seco com uma estação seca longa e um período frio com geadas (Behling 1998). Stehmann (1999) sugeriu a existência de uma rota migratória de ancestrais de Calibrachoa através do pampa, atingindo o planalto das araucárias e algumas serras do sudeste do Brasil. Silveira \& Cure (1993), estudando o padrão de distribuição geográfica da fauna apícola nas regiões de altitude do sudeste do Brasil, encontraram um grupo de espécies ocorrendo nas montanhas do sudeste do Brasil e em latitudes superiores a $24^{\circ} \mathrm{S}$ no sul do Brasil e sugeriram que tais espécies poderiam ser remanescente de uma fauna associada com a vegetação subtropical e temperada que avançou para o norte nos períodos frios. Hexantheda missionica apresenta esse padrão de distribuição geográfica e as populações disjuntas de $H$. missionica encontradas nas regiões de altitude da região sudeste do Brasil, como a área do quadrilátero ferrífero de Minas Gerais, podem ser interpretadas como remanescentes de populações que permaneceram confinadas no topo das montanhas quando o clima tornou-se mais quente.

No sul do Brasil, há regiões onde mais de uma espécie de abelha é encontrada visitando e utilizando os recursos de flores de uma ou mais espécies de Calibrachoa (Wittmann et al. 1990, Schlindwein 1995, Stehmann 1999). A dependência de C. elegans de um único polinizador pode ser interpretada como decorrente do confinamento histórico de populações marginais das duas espécies. Segundo Feinsinger (1983), a dependência da população de uma planta de uma simples espécie de abelha polinizadora freqüentemente conduz à especiação da planta e especialização comportamental e fisiológica para a abelha, processo esse que parece ter ocorrido entre Calibrachoa-Hexantheda. O isolamento propiciou a aquisição de diferentes características morfológicas pelas populações da planta, algumas adaptativas ao estresse hídrico da região da canga, como as folhas hipostomáticas com a margem revoluta e superfície abaxial coberta de espesso indumento, culminando em especiação, enquanto que as populações de Hexantheda parecem ter sofrido pouca alteração morfológica.

O sistema de auto-incompatibilidade gametofítico encontrado em $C$. elegans é o mesmo descrito para outros gêneros de Solanaceae, tais como Nicotiana e Solanum (Mather 1943, Linskens 1975).
As bases bioquímicas e genéticas desse sistema têm sido intensamente estudados em Solanaceae (Linskens 1975, Herrero \& Dickinson 1979, Broothaerts et al. 1991, Golz et al. 1995). A presença de auto-incompatibilidade indica que a polinização cruzada deve ser obrigatória para que as populações tenham sucesso reprodutivo. Qualquer perturbação no sistema, que afete a população do polinizador, afetará consequentemente a sobrevivência das populações de C. elegans.

Calibrachoa elegans floresce na primavera e no verão, embora possa ser encontrada em flor em outros períodos do ano. Seu sucesso reprodutivo, contudo, deve depender do ajuste do período de florescimento com o ciclo de vida univoltino de Hexantheda missionica. O florescimento em épocas em que o polinizador está ausente provavelmente não acarretará na formação de frutos.

Calibrachoa elegans foi considerada uma espécie criticamente em perigo, estando ameaçada pela destruição do seu habitat, pela área de distribuição restrita e pelas populações pequenas e isoladas. Além disso, o fato da espécie ser auto-incompatível e dependente da polinização por uma única espécie de abelha, torna-a mais suscetível ao risco de extinção. A mineração da hematita (minério de ferro) é aberta e a cobertura vegetal, bem como o solo, são totalmente removidos, havendo impacto direto tanto sobre as populações da planta, como provavelmente sobre as populações de seu polinizador, Hexantheda missionica. Informações sobre a biologia de $H$. missionica, indicando os locais de nidificação, bem como sobre a dinâmica das populações de $C$. elegans, se tornam importantes para o planejamento das estratégias para a conservação da espécie e, consequentemente, para diminuir o risco de extinção da espécie.

Agradecimentos - Agradecemos a Clemens Schlindwein e a Fernando Silveira pela identificação das abelhas e a Cláudia Maria Jacobi, Edivani Franceschinelli e Julie Dutilh pela leitura crítica do manuscrito.

\section{Referências bibliográficas}

BEHLING, H. 1998. Late Quaternary vegetational and climatic changes in Brazil. Review of Palaeobotany and Palynology 99:143-156. 
BROOTHAERTS, W., VANVINCKENROYE, P., DECOCK, B., VAN DAMME, J. \& VENDRIG, J.C. 1991. Petunia hybrida S-proteins: ribonuclease activity and the role of their glycan side chains in self-incompatibility. Sexual Plant Reproduction 4:258-266.

BRUMMITT, R.K. 1989. Report of the Committee for Spermatophyta:36. Taxon 38:301.

CHITTKA, L. \& MENZEL, R. 1992. The evolutionary adaptation of flower colours and the insect pollinators' colour vision. Journal of Comparative Physiology A, Sensory, Neural, and Behavioral Physiology 171:171-181.

COPAM. 1997. Deliberação COPAM n 85, 30 de outubro de 1997. Conselho Estadual de Política Ambiental, Belo Horizonte, 1 cad., p.10-12.

DAFNI, A., IVRI, Y. \& BRANTJES, N.B.M. 1981. Pollination of Serapias vomeracea Briq. (Orchidaceae) by imitation of holes for sleeping solitary male bees (Hymenoptera). Acta Botanica Neerlandica 10:69-73.

FERGUSON, M.C. \& OTTLEY, A.M. 1932. Studies in Petunia. II. A redescription and additional discussion of certain species of Petunia. American Journal of Botany 19:385-407.

FEINSINGER, P. 1983. Coevolution and pollination. In Coevolution (D.J. Futuyama \& M. Slatkin, eds). Sinauer Associates Inc., Sunderland, p.282-310.

GOLZ, J.F., CLARKE, A.E. \& NEWBIGIN, E. 1995. Self-incompatibility in flowering plants. Current Opinion in Genetics \& Development 5:640-645.

HERRERO, M. \& DICKINSON, H.G. 1979. Pollen-pistil incompatibility in Petunia hybrida; changes in the pistil following compatible and incompatible intraspecific crosses. Journal of Cell Science 36:1-18.

KEVAN, P.G. 1983. Floral colors through the insect eye: What they are and what they mean. In Handbook of experimental pollination biology (C.E. Jones \& R.J. Little, eds.). Scientific and Academic Editors, New York, p.3-30.

LINSKENS, H.F. 1975. Incompatibily in Petunia. Proceedings of the Royal Society of London, ser. B, 188:299-311.

MARTIN, F.W. 1959. Staining and observing pollen tubes in the style by means of fluorescence. Stain Technology 37:125.

MATHER, K. 1943. Specific differences in Petunia. I. Incompatibility. Journal of Genetics 45:215-235.

MICHENER, C.D. 1989. Classification of American Colletidae (Hymenoptera, Apoidea). The University of Kansas Science Bulletin 53:622-703.

RIZZINI, C.T. 1979. Tratado de fitogeografia do Brasil. 2 ed. Hucitec/ Editora da Universidade de São Paulo, São Paulo.

ROUBIK, D.W. 1989. Ecology and natural history of tropical bees. Cambridge University Press, Cambridge.
SCHLINDWEIN, C. 1995. Wildbienen und ihre trachtpflanzen in einer sudbrasilianischen buschlandschaft fallstudies Guaritas, bestaubung bei kakteen und loasaceen. Ulrich E. Grauer, Sttutgart.

SILVA, O.S. 1994. Importância da Callonychium petuniae Cere \& Wittmann, 1990 (Insecta, Hymenoptera, Andrenidae) e outras abelhas no sucesso reprodutivo de Petunia integrifolia (Hooker) Schinz et Thellung (Solanaceae). Dissertação de mestrado, Pontifícia Universidade Católica do Rio Grande do Sul, Porto Alegre.

SILVEIRA, F.A. \& CURE, J.R. 1993. High-altitude bee fauna of southeastern Brazil: Implications for biogeographic patterns (Hymenoptera: Apoidea). Studies on Neotropical Fauna and Environment 28:47-55.

SMITH, L.B. \& DOWNS, R. 1966. Solanáceas. Flora Ilustrada Catarinense (fasc. SOLA):1-321.

STEHMANN, J.R. \& SEMIR, J. 1997. A new species and new combinations in Calibrachoa (Solanaceae). Novon 7:417-419.

STEHMANN, J.R. 1999. Estudos taxonômicos na tribo Nicotianeae (Solanaceae): revisão de Petunia Jussieu, das espécies brasileiras de Calibrachoa La Llave \& Lexarza e o estabelecimento do novo gênero Petuniopsis Stehmann \& Semir. Tese de doutorado, Universidade Estadual de Campinas, Campinas.

VOGEL, S. 1962. Die duftdrüsen der orchideen. Akademie der Wissenschaften und der Literatur: Abhandlungen der mathematisch-naturwissenschaftlichen Klasse 10:603-763.

WIJSMAN, H.J.W., JONG, J.H. \& PEDERSEN, T.M. 1983. On the interrelationships of certain species of Petunia. III. The position of $P$. linearis and $P$. calycina. Acta Botanica Neerlandica 32:323-332.

WIJSMAN, H.J.W. \& JONG, J.H. 1985. On the interrelationships of certain species of Petunia. IV. Hybridization and nomenclatural consequences in the Petunia group. Acta Botanica Neerlandica 34:337-349.

WIJSMAN, H.J.W. 1990. On the inter-relationships of certain species of Petunia VI. New names for the species of Calibrachoa formerly included into Petunia (Solanaceae). Acta Botanica Neerlandica 39:101-102.

WITTMANN, D., RADTKE, R., CURE, J.R. \& SCHIFINO-WITTMANN, M.T. 1990. Coevolved reproductive strategies in the oligolectic bee Callonychium petuniae (Apoidea, Andrenidae) and three purple flowered Petunia species (Solanaceae) in southern Brazil. Zeitschrift für zoologische Systematik und Evolutionsforschung 28:157-165.

ZEISLER, M. 1938. Über die abgrenzung der eigentlichen narbenfläche mit hilfe von reaktionen. Beihefte zum Botanischen Centralblatt 58:308-318. 